\title{
Os determinantes do desenvolvimento (catchíng up) na abordagem neoschumpeteriana: integrando a teoria microeconômica evolucionária com conceito de revoluções tecnológicas
}

Herton Castiglioni Lopes ${ }^{1}$

Resumo: o texto objetiva integrar a teoria microeconômica evolucionária com a ideia de revoluções tecnológicas e seus desdobramentos, reunindo elementos que ajudam a explicar o desenvolvimento econômico (catching up) das nações ao longo do tempo. Os autores neoschumpeterianos mantêm foco no estudo da inovação e fornecem uma série de análises complementares, sem as quais é impossível compreender os diferenciais de desenvolvimento entre os países. A partir do que está proposto, observa-se que o desenvolvimento acontece diante do progresso técnico, quando se abrem as janelas de oportunidade de uma revolução tecnológica, que faz surgir novos paradigmas tecnoeconômicos e direciona a inovação no âmbito das firmas.

Palavras-chave: Desenvolvimento. Neoschumpeterianos. Inovação. Progresso técnico.

Abstract: the aim of this text is to integrate the micro-economical fundaments from evolutionary approach with concepts of technological revolutions and their consequences bringing elements to explain economic

1 Doutor em Economia pela Universidade Federal do Rio Grande do Sul (UFRGS). Professor Adjunto da Universidade Federal da Fronteira Sul (UFFS). 
development (catching up) of nations a long time.. Authors neo-schumpeterian keep focus on studies of innovation and supply a lot of complementary analyses, without them it is impossible to understand the differences of developing among the countries. The results show that the development occurs through the technical progress, when the windows of opportunity open from a technological revolution that brings new techno-economic paradigm and direct the innovation in the scope of the companies.

Keywords: Development. Neo-schumpeterian. Innovation. Technical progress.

JEL: B15; B52; O30

\section{Introdução}

Claro que a teoria evolucionária de que estou falando é fortemente schumpeteriana. É interessante, e relevante, que em sua Teoria do Desenvolvimento Econômico, Schumpeter usou o conceito de equilíbrio no fluxo circular, onde o comportamento habitual e costumeiro eram suficientes, na verdade perigoso de ser abandonado, tratava-se de um veículo para se contrastar o que está envolvido na economia do desenvolvimento, onde a inovação estava dirigindo mudança, e o sistema estava fora do equilíbrio. ${ }^{2}$ (NELSON, 2007, p. 3-4)

Alcançar o desenvolvimento supõe um processo dinâmico, alimentado por inovações locais e mercados crescentes, no qual se teria que ingressar tão cedo fosse possível. ${ }^{3}$ (PEREZ, 2001, p. 75)

\footnotetext{
2 "Of course the evolutionary theory I am talking about is strongly Schumpeterian. It is interesting, and relevant, that in his Theory of Economic Development, Schumpeter used the concept of a circular flow equilibrium, where habitual, customary, behavior sufficed, indeed was hazardous to abandon, as the vehicle to contrast with what is involved in economic development, where innovation was driving change, and the system was out of equilibrium". (NELSON, 2007, p. 3-4)

3 "Alcanzar el desarrollo supone um proceso dinámico, alimentado por innovaciones locales y mercados crecientes, por lo cual habría que ingresar tan temprano como fuera posible". (PEREZ, 2001, p. 75)
} 
Que a inovação é elemento chave na explicação do desenvolvimento parece não restar dúvidas. Foi Joseph A. Schumpeter, ${ }^{4}$ em meio à supremacia da teoria ortodoxa, quem ousou demonstrar que a compreensão do desenvolvimento requer um estudo das rupturas e desequilíbrios que acontecem ao longo da história do capitalismo. Seu legado deu origem à ascensão de autores que aprofundam a análise da inovação como elemento determinante das diferentes performances das economias ao longo do tempo. Os neoschumpeterianos, além de focarem a inovação como fonte das descontinuidades, incorporam conceitos que se desdobram na explicação do desenvolvimento e servem para interpretar não apenas o caso dos países avançados, mas daqueles que procuram alcançar as nações de ponta.

Partindo da teoria derivada de Schumpeter, o texto objetiva integrar a teoria microeconômica evolucionária com a ideia de revoluções tecnológicas e seus desdobramentos, reunindo elementos que ajudam a explicar o desenvolvimento econômico (catching up) das nações ao longo do tempo. Sua principal contribuição é unir a abordagem neoschumpeteriana da firma com os conceitos de revoluções, paradigmas, trajetórias tecnológicas e janelas de oportunidades, de forma a explicar as diferentes performances das economias. Além disso, propõe tratar o progresso técnico como a instituição chave do crescimento, mas demonstrando sua relação com as demais instituições socioeconômicas.

Ao propor essas metas, o artigo reconhece que existe espaço para uma sistematização teórica, capaz de reunir conceitos neoschumpeterianos que deem conta de explicar o fenômeno do desenvolvimento. A proposta oferece subsídios para se compreender as razões de algumas nações menos desenvolvidas avançarem (forging ahead) e alcançarem os países de ponta (catching up) enquanto outras são ultrapassadas (falling behind) e não conseguem alavancar seus níveis de produtividade. Seguindo essa linha conceitual, o texto propõe que o desenvolvimento econômico difere da simples noção de crescimento quando se trata dos países menos avançados. O primeiro requer catching up, enquanto o segundo se resume a aumentos do Produto Interno Bruto (PIB) per capita sem mudança tecnológica, institucional, estrutural e, mais importante, sem aproveitamento das oportunidades abertas em cada revolução. Por isso, para se analisar o desenvolvimento, é preciso qualificar a inovação, demonstrando que ela deve acontecer em

4 "O desenvolvimento é visto como um processo de mudança, determinado pelas inovações que ocorrem no modo capitalista de produção. O responsável é o empresário schumpeteriano que se utiliza do crédito para realizar as novas combinações e só recebe essa denominação porque, em busca do lucro, é capaz de promover inovações que se disseminam junto aos demais produtores, causando os ciclos de desenvolvimento econômico". (SCHUMPETER, 1984, p. 1985) 
convergência com a revolução tecnológica em curso e com o paradigma tecnoeconômico em desenvolvimento, num momento em que se abrem as verdadeiras oportunidades tecnológicas.

Com vistas a atender a proposta de trabalho, além desta introdução, o item 2 aborda o desenvolvimento aliado aos conceitos de revoluções e trajetórias tecnológicas, paradigmas tecnoeconômicos e janelas de oportunidade. Contudo, essa teoria necessita de uma abordagem microeconômica que incorpore o papel das firmas no progresso técnico e na evolução da tecnologia. Assim, o item 3 trata da teoria da firma que se utiliza da metáfora evolucionária para explicar o comportamento e sobrevivência das empresas, assim como o desenvolvimento. Enfim, o item 4 traz a proposta de sistematização de conceitos que permitem interpretar o desempenho das nações ao longo do tempo.

\section{0 desenvolvimento (catchíng up) e os conceitos de revoluções tecnológicas, paradigmas tecnoeconômicos e janelas de oportunidade}

As grandes inovações e o progresso técnico de ponta acontecem em regiões ou nações específicas e não se distribuem de forma homogênea nos diversos países do mundo. Por isso, a concepção de desenvolvimento requer observar o que se entende por revoluções tecnológicas e os desdobramentos delas decorrentes. O conceito de revoluções tecnológicas, amplamente discutido em Carlota Pérez (1992, 2001, 2004, 2009) e desenvolvido em conjunto com Christopher Freeman (VELHO, 2010), observa que ciclos de crescimento se iniciam a partir de inovações radicais que modificam o método de produzir da economia. ${ }^{5}$

Essas revoluções criam novos paradigmas, questão discutida em Dosi $(1988,1993)$ a partir de uma conotação microeconômica. Traçando paralelos com a filosofia da ciência, G. Dosi observou que no campo econômico as revoluções são como as científicas, conforme tratadas em Thomas Khun (1992). Assim como as revoluções no campo científico mudam a forma de fazer ciência, consolidando novas práticas e abrindo espaço para a ciência normal, as revoluções tecnológicas rompem com as antigas práticas fazendo emergir novos arranjos e formas de produzir.

5 Não é por acaso que Conceição (2002) trata os conceitos de revoluções tecnológicas e paradigmas tecnoeconômicos como pertencentes ao modelo Freeman-Pérez. 
A revolução está intimamente relacionada com o fenômeno do desenvolvimento, porque este deve ser entendido a partir de grandes ondas que ocorrem a cada cinco ou seis décadas, gerando mudanças estruturais significativas em toda a sociedade. ${ }^{6}$ As ondas acontecem quando uma revolução tecnológica e seu paradigma se propagam, modificando a estrutura de produção, distribuição, comunicação e consumo da economia. (PÉREZ, 2004) Assim, revoluções tecnológicas podem ser definidas como "[...] um poderoso e visível conjunto de tecnologias, produtos e indústrias novas e dinâmicas, capazes de abalar os alicerces da economia e impulsionar uma onda de desenvolvimento de longo prazo". ${ }^{7}$ (PÉREZ, 2004, p. 32)

Para Pérez (2004), uma revolução tecnológica passa por duas etapas distintas: um intervalo de instalação e outro de desprendimento, cada qual durando cerca de 20 ou 30 anos. O primeiro intervalo subdivide-se em dois períodos: um de irrupção, quando acontece um grande salto na produtividade das tecnologias relacionadas ao novo paradigma produtivo, e outro chamado de frenesi, quando o comportamento frenético do capital financeiro, em busca de lucros associados a novas tecnologias, faz surgir bolhas financeiras. Com a crise, aparece a necessidade de regulamentação estatal e reestruturação institucional, que gera um intervalo de acomodação abrindo possibilidades para uma segunda etapa: a de desprendimento ou difusão, que se subdivide em uma fase de sinergia, com expansão do potencial inovativo e de mercado, e uma fase de maturidade, com oportunidades de investimento decrescentes e capital ocioso que se movimenta em busca de maiores lucros.

A forma de inserção das nações em cada revolução tecnológica define as potencialidades de emergência à condição de país desenvolvido. As cinco revoluções, bem com o local de sua ocorrência, são apresentadas na primeira coluna do quadro a seguir (revolução industrial; era do vapor e das ferrovias; era do aço e da eletricidade; era do automóvel e da produção em massa; e era da informática e da sociedade do conhecimento).

6 A noção de revoluções tecnológicas e sua relação com os estágios de desenvolvimento foi desenvolvida a partir dos estudos de Nikolai Kondratieff nos anos 1920. Maiores esclarecimentos podem ser encontrados em Pérez (1983).

7 “[...] un poderoso y visible conjunto de tecnologías, productos e industrias nuevas y dinámicas, capaces de sacudir los cimientos de la economía y de impulsar una oleada de desarrollo de largo plazo". (PÉREZ, 2004, p. 32) 


\begin{tabular}{|c|c|c|c|}
\hline 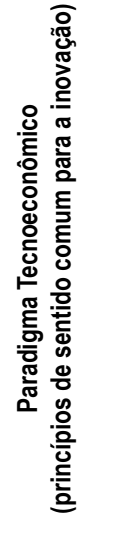 & 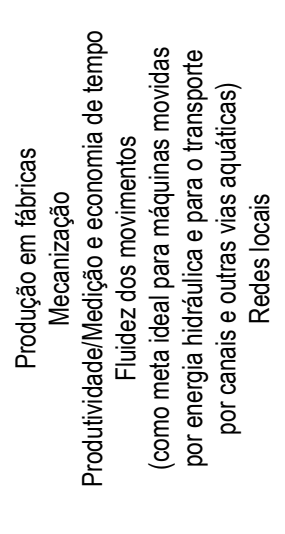 & 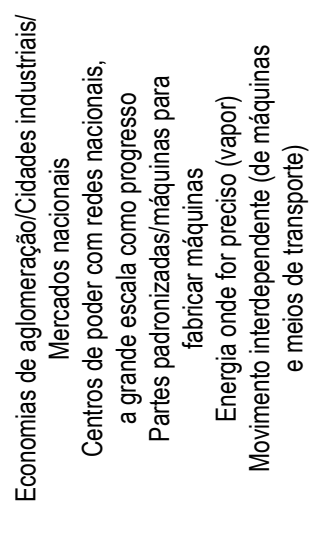 & 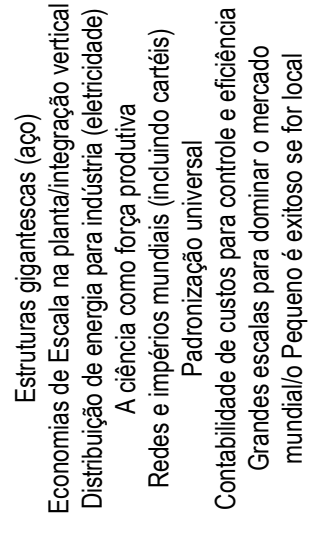 \\
\hline 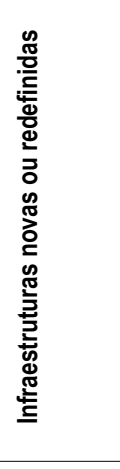 & 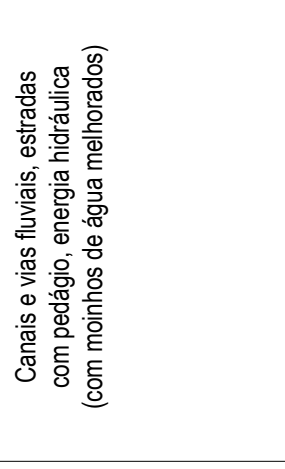 & 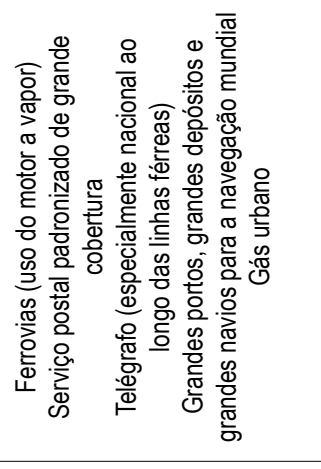 & 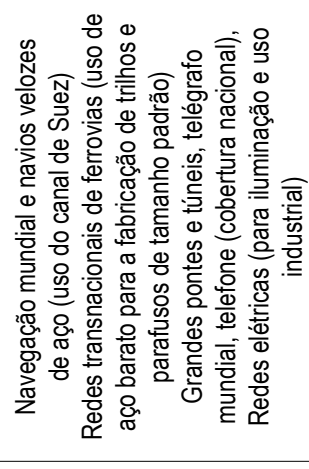 \\
\hline 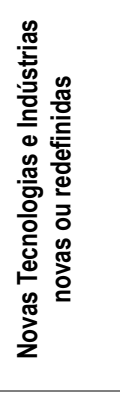 & 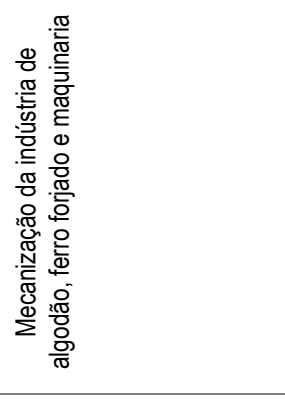 & 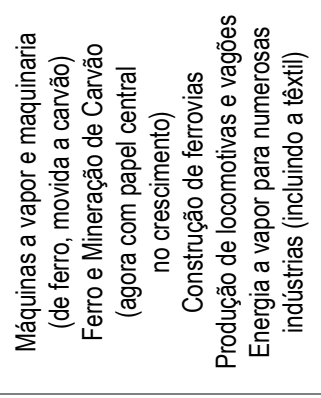 & 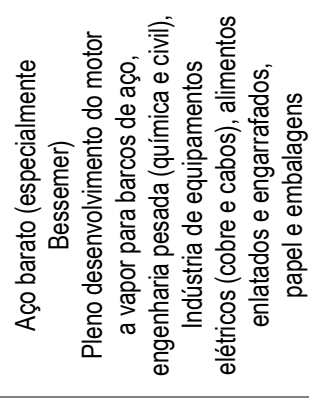 \\
\hline 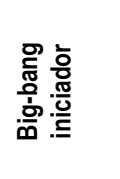 & 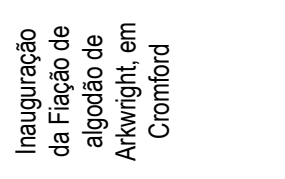 & 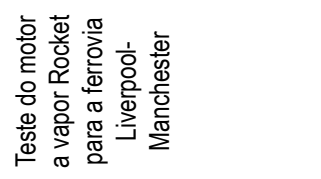 & 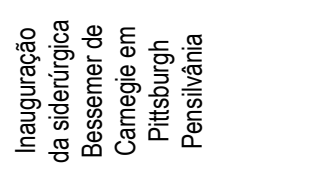 \\
\hline 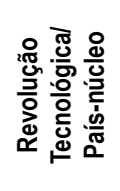 & 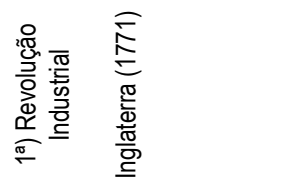 & 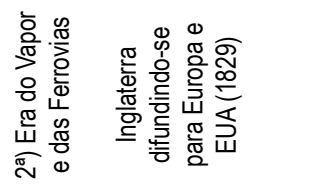 & 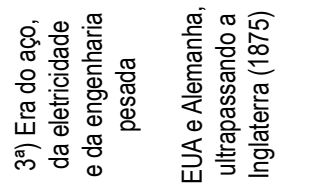 \\
\hline
\end{tabular}




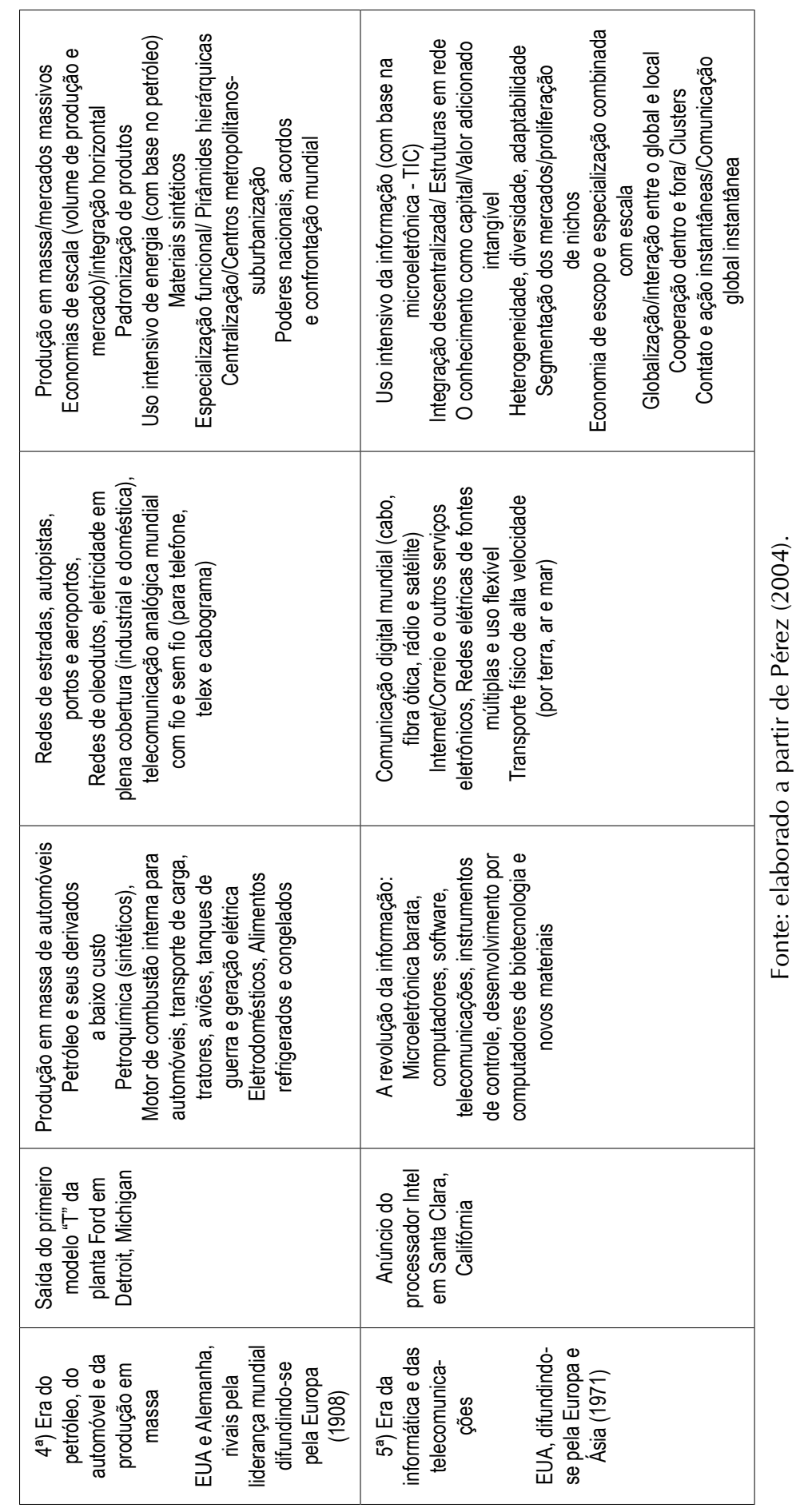


As revoluções tecnológicas ocorrem com um fator iniciador, o surgimento de uma inovação que define a direção para o desenvolvimento das novas tecnologias. Esse fator iniciador, o "big-bang", é também chamado por Pérez (2004) de atrator. ${ }^{8}$ Isso porque ele desperta um novo potencial de evolução técnica e faz surgir a imaginação tecnológica e de negócio de uma série de empreendedores pioneiros. Não basta, porém, ser uma simples evolução de novidades práticas. É necessário que tenha um baixo custo e que as inovações sejam capazes de trazer rentabilidade às firmas precursoras na utilização da nova forma de produção (coluna 2 - Quadro 1).

Uma revolução se transforma em uma "constelação de inovações" que altera o modo de produção e as condições de desenvolvimento das nações que são atingidas. Para Pérez (2001, 2004), essas novidades tecnológicas se inter-relacionam com as indústrias jovens e antigas, fazendo emergir uma verdadeira transformação produtiva (coluna 3 - Quadro 2). As novas tecnologias, em conjunto com indústrias jovens ou redefinidas, carecem ainda de uma nova infraestrutura. Ou seja, para viabilizar a utilização das novas técnicas pelas indústrias, é necessário eliminar as possibilidades de estrangulamento estrutural (coluna 4 - Quadro 1). Finalmente, as revoluções tecnológicas, o "big-bang" iniciador, as novas tecnologias, indústrias e a infraestrutura de cada revolução tecnológica definem o surgimento do novo paradigma tecnoeconômico (coluna 5 - Quadro 1).

Ao contrário da ideia desenvolvida por Dosi $(1988,1993)$, o paradigma tecnoeconômico possui uma conotação sistêmica porque diz respeito a todo conjunto de fatores que estimula e define a forma de operar das empresas. Para Conceição (2002), ao vincular-se à periodização dos ciclos longos, o conceito apresenta características mais agregativas ou macroeconômicas. Também incorpora, além da dimensão técnica, a dimensão econômica e institucional que afeta as inovações e o progresso tecnológico. ${ }^{9}$

Observa-se, dessa forma, que os conceitos descritos estão inter-relacionados e são complementares. As novas práticas serão definidas pelo novo paradigma tecnoeconômico, sendo este influenciado pela revolução tecnológica, pelas novas indústrias, tecnologias e infraestrutura em transformação. Ou seja, a revolução tecnológica, que tem um fator iniciador,

8 Em Pérez (1983) fala-se de fator-chave (key factor) associado ao big bang inicial. Ele deve possuir as seguintes características: custo relativo baixo e descendente; disponibilidade ilimitada; amplo espectro de utilização potencial e capacidade para reduzir os custos do capital, do trabalho e dos produtos, modificando-os qualitativamente. Na quinta revolução industrial, por exemplo, se relaciona ao uso da microeletrônica com baixos investimentos.

9 Conceição (2002) afirma que Carlota Perez prefere a denominação de "paradigma tecnoeconômico" em vez de "paradigma tecnológico", de Giovani Dosi, ou "trajetórias naturais", de Nelson e Winter. Isso devido à maior abrangência da primeira expressão, que se associa a características institucionais e sociais inerentes a cada novo paradigma. 
define as possibilidades de utilização das tecnologias em desenvolvimento. A nova constelação de indústrias e tecnologias, em conjunto com a nova infraestrutura, irá modificar significativamente a forma de fazer negócios na economia.

O paradigma tecnoeconômico torna-se um guia para se aproveitar ao máximo as potencialidades abertas pela revolução em curso. Ele define novas práticas coletivas, que servem para orientar as decisões de todos os agentes ligados ao processo produtivo. É um roteiro para inovação, um guia para a decisão dos empresários, inovadores, gerentes, administradores e investidores em busca da maior eficiência. (PÉREZ, 2001) Trata-se de um tipo ideal de organização do sistema produtivo, o estabelecimento de um sentido do que se acredita ser a melhor opção tecnológica. (PÉREZ, 1983) Nas palavras de Pérez (2004), um paradigma tecnoeconômico é:

\begin{abstract}
[...] um modelo de prática ótma constituído por um conjunto de princípios tecnológicos e organizativos, genéricos e ubíquos, que representam a forma mais adequada de aplicar a revolução tecnológica e usá-la para modernizar e rejuvenescer o resto da economia. Quando sua adoção se generaliza, estes princípios se convertem na base de sentido comum para a organização de qualquer atividade e reestruturação de qualquer instituição. ${ }^{10}$ (PEREZ, 2004, p. 41)
\end{abstract}

A construção do novo paradigma ocorre simultaneamente da seguinte forma: em primeiro lugar, ela modifica a dinâmica de custos relativos dos insumos utilizados na estrutura produtiva. Nesse caso, as despesas são decrescentes e estimulam a inovação e os investimentos, que se tornam mais atrativos. Em segundo, as oportunidades para inovação são crescentemente mapeadas pelos empresários, visando utilizá-las em novas indústrias ou nas já existentes. Enfim, modificam-se os critérios e princípios organizacionais, em que a nova prática continua a mostrar desempenho superior, possibilitando tirar proveito do poder das novas tecnologias para melhor eficiência e lucros mais elevados. (PÉREZ, 2009) Como resultado das novas tecnologias, Pérez (1992) afirma que a produtividade geral da economia tende a ser substancialmente ampliada e acontece "[...] um

10 "[...] um modelo de óptima práctica constituido por un conjunto de principios tecnológicos y organizativos, genéricos y ubicuos, el cual representa la forma más afectiva de aplicar la revolución tecnológica y usarla para modernizar y rejuvenecer el resto de la economía. Cuando su adopción se generaliza, estos principios se convierten en la base del sentido común para la organización de cualquier actividad y la reestructuración de cualquier institución". (PEREZ, 2004, p. 41) 
rejuvenescimento gradual de toda a estrutura produtiva, de modo que as indústrias maduras atualizadas podem voltar a comportar-se como indústrias novas, no que diz respeito ao dinamismo, produtividade e rentabilidade". ${ }^{11}$ (PÉREZ, 2009, p. 14)

Como a revolução tecnológica acontece em algum país ou região específica, o desenvolvimento das nações vai ser determinado por sua capacidade em aproveitar as mudanças em curso. Tal fato foi tratado em Abramovitz (1986) e aprofundado nos diversos trabalhos de Carlota Pérez. Abramovitz (1986) demonstra que a possibilidade de alcançar os países de ponta é maior quando o gap de produtividade entre esses e os em desenvolvimento é grande. Nesse caso, a implantação de novas tecnologias nos países mais atrasados tende a amenizar as divergências de crescimento. Porém, esse não é o único elemento, pois existe ampla necessidade de capacitações sociais. Somente assim as oportunidades tecnológicas em curso serão adequadamente aproveitadas, reduzindo as diferenças produtivas.

Para os países que não são precursores da revolução tecnológica, as mudanças de paradigma representam oportunidades para avançar (forging ahead) e alcançar os desenvolvidos (catching up), ou serem ultrapassados (falling behind). As chances de desenvolvimento abertas em cada revolução recebem o tratamento de janelas de oportunidade. Segundo Perez (2001), um "alvo móvel" a ser atingido pelos países mais atrasados, que devem modificar suas técnicas exatamente quando se abrem as potencialidades do novo paradigma. A melhor ocasião acontece quando são desenvolvidos novos produtos, novas indústrias e novas tecnologias, porém, sendo necessárias pessoas qualificadas para colocar em curso as inovações tecnológicas que emergem a cada nova revolução. ${ }^{12}$ Se os países tardarem em implantar as novas técnicas produtivas, os produtos e as tecnologias entrarão em fase de maturação, podendo sua contribuição para o desenvolvimento ser reduzida.

A janela de oportunidade está, portanto, relacionada com a fase de evolução das novas tecnologias (fase da revolução tecnológica). Em função disso, é importante destacar que a possibilidade de catching up é fortemente influenciada pela trajetória tecnológica que se desenha em cada revolução. A trajetória se refere ao fato de grande parte das tecnologias

11 "[...] un rejuvenecimiento gradual de toda la estructura productiva, de modo que las industrias maduras actualizadas puedan volver a comportarse como industrias nuevas, en cuanto a dinamismo, productividad y rentabilidad". (PÉREZ, 2009, p. 14)

12 Para Pérez (2001), não basta a transferência tecnológica, pois a absorção das inovações envolve esforços significativos para adotar e adaptar determinados conhecimentos técnicos que viabilizam a melhor utilização das potencialidades tecnológicas. 
seguir um curso similar desde a inovação inicial até a sua maturação. (PERÉZ, SOETE, 1988; PÉREZ, 2001; 2004) Trata-se de uma ideia muito semelhante ao que acontece no mercado de produtos, conforme se observa na figura a seguir.

Figura 1 - Trajetória tecnológica

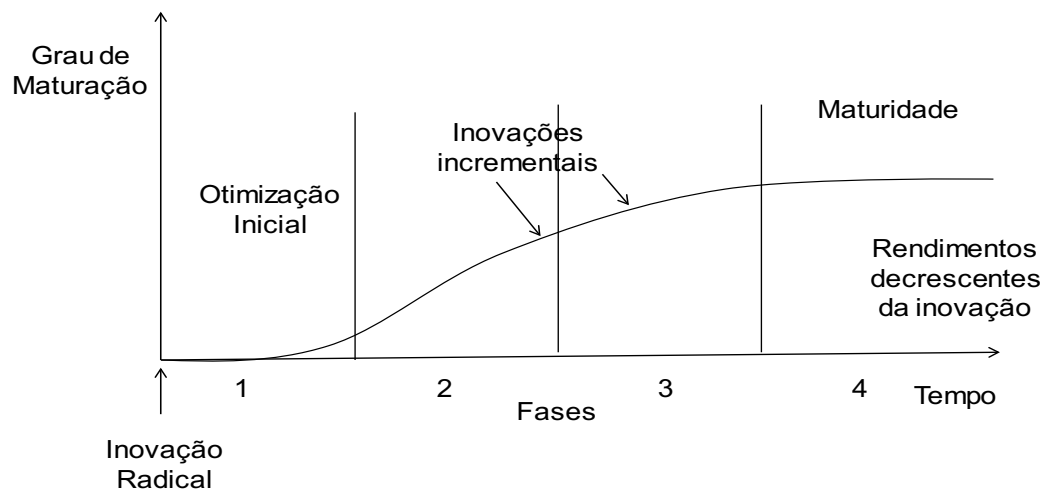

Fonte: Pérez (2001, 2004).

De acordo com a ilustração, inicialmente acontece uma inovação radical determinando o aparecimento de um novo produto (tecnologia) que sustenta o desenvolvimento de uma indústria. Esse período inicial é marcado por uma sequência de inovações e é quando acontece a "otimização inicial". Em seguida, as novas tecnologias passam por uma sequência de inovações incrementais, visando melhorar a qualidade, a produtividade e a posição dos produtores na indústria. Quando as inovações incrementais acarretam rendimentos decrescentes, o produto entra em sua fase de maturação. O período inicial, logo após a inovação radical, é caracterizado como crucial para o crescimento dos países. Isso porque é o momento em que ocorrem a aprendizagem e as possibilidades de melhor aproveitamento das técnicas em desenvolvimento. 


\section{Os fundamentos microeconômicos: o papel das firmas e $o$ processo evolutivo}

Temos a satisfação em explorar qualquer ideia da biologia que pareça útil à compreensão de problemas econômicos, mas estamos igualmente preparados para ignorar qualquer coisa que pareça estranha, ou para modificar teorias biológicas aceitas em prol do desenvolvimento de uma melhor teoria econômica. (NELSON; WINTER, 2005, p. 28)

No âmbito microeconômico, a teoria neoschumpeteriana procura explicar o comportamento da firma e o funcionamento dos mercados a partir de uma teoria evolucionária, com a apropriação de conceitos da Biologia para interpretar o desenvolvimento. Ao fazer isso, prioriza uma análise crítica e diferenciada da tradição ortodoxa, que não consegue explicar o desenvolvimento como um fenômeno endógeno ao modo de produção. Em vez das tradicionais análises de equilíbrio, os evolucionários estão preocupados com os desequilíbrios e a mudança, que criam diferentes trajetórias de desenvolvimento.

O trabalho seminal sob a perspectiva microeconômica evolucionária é a obra de Nelson e Winter (2005), intitulada Uma teoria evolucionária da mudança econômica. Nela, as firmas são as unidades de análise, merecedoras de especial atenção por se tratarem do local propício à inovação. ${ }^{13} \mathrm{O}$ enfoque dos autores está no processo de tomada de decisão das empresas que leva a melhores condições operacionais. Contudo, essa decisão, em vez de ser determinada pelo comportamento maximizador suposto na teoria tradicional, assume o contorno de rotinas que se tornam relativamente estáveis ao longo do tempo, mas podem modificar-se para proporcionar melhor resultado econômico. Trata-se de uma concepção de agente, racionalidade e comportamento que se assemelha à desenvolvida

13 Apesar de essa obra ser reconhecida como marco teórico na abordagem microeconômica evolucionária, os autores publicaram muitos conceitos importantes na obra In search of useful theory of innovation, de 1977. 
por Herbert Simon ${ }^{14}$ ao demonstrar que os indivíduos não conseguem ser racionais, mas procuraram as opções mais adequadas para os problemas observados em determinados contextos. Nas palavras de Nelson e Winter (2005, p. 36): "[...] a qualquer momento do tempo, as rotinas historicamente dadas governam as ações de uma empresa".

As rotinas são classificadas em três tipos: em primeiro lugar estão as operacionais, que dizem respeito aos procedimentos com equipamentos ou fatores que não podem ser imediatamente modificados. Em segundo, existem as rotinas que determinam o aumento ou redução no estoque de capital empregado, ou seja, rotinas para determinar os novos investimentos e o nível de capacidade produtiva. Enfim, existem as rotinas capazes de modificar rotinas. Ou seja, em determinados períodos as empresas podem modificar várias das suas características e repensar toda sua forma de operação.

É interessante observar que no modelo dos autores, o desenvolvimento de rotinas acontece a partir de um processo de "busca" (search). Em outras palavras, a modificação das rotinas decorre de um exame cuidadoso por parte da empresa e será altamente influenciada pela capacidade das novas rotinas em proporcionar maior lucratividade. As firmas apresentam, dessa forma, um comportamento característico que procura inovações que gerem novas rotinas. Esse processo de busca não é determinístico, pois resulta de um processo estocástico de erros e acertos por parte dos agentes. Não é por acaso que Rosemberg (2006) questiona a exogeneidade da ciência demonstrando, com diversos exemplos, que as tecnologias e a pesquisa científica se desenvolvem a partir dos problemas observados na prática cotidiana das empresas.

As firmas e, portanto, as rotinas, como resultado desse processo de investigação, estão sujeitas a um processo evolucionário. Aquelas com

14 Hebert Simon é referência em qualquer texto que aborde comportamento a partir das limitações cognitivas dos agentes. Para Simon (1986), a economia apresenta uma inclinação a afirmar que os seres humanos são racionais. Contudo, trata-se de um conceito de racionalidade diferente da Psicologia e das demais ciências sociais. Em vez da racionalidade substantiva, o autor dá enfoque ao conceito de racionalidade procedimental, que procura tratar empiricamente a natureza, a origem dos valores e as mudanças de preferências que ocorrem com o tempo. Procura, ainda, analisar os processos sociais e individuais da realidade, explicando as formas como os processos não racionais, tais como motivações, emoções e estímulos não sensoriais, influenciam no processo racional. Simon (1965), após explorar os limites da racionalidade, também observa a necessidade de se reconhecer os hábitos na conduta dos agentes, pois permitem conservar comportamentos diante de situações repetitivas. Segundo Simon (1965, p. 105), "O hábito não deve ser encarado como um elemento puramente passivo (tanto do indivíduo como da organização), pois uma vez formado, a simples presença do estímulo tende a ativar o comportamento habitual, sem outro pensamento consciente". No processo produtivo, um hábito deve ser entendido como uma rotina, que leva a resultados não ótimos, mas satisfatórios. (NELSON, 2007) 
rotinas mais adequadas às condições de mercado são as que possuem maior capacidade de sobrevivência e estarão mais aptas ao crescimento e aquisição de grande parcela da indústria. Fica evidente que esse processo é determinado historicamente ou pela trajetória de cada firma no mercado. As rotinas acumuladas e o conhecimento observado no interior das empresas são resultado da sua evolução histórica, onde operam mecanismos de seleção e adaptação conforme as análises biológicas transparecem.

Exatamente por isso, Hodgson (1997) afirma que a teoria de Nelson e Winter representa uma autêntica teoria evolucionária, já que as rotinas das empresas são vistas como os genes da Biologia. A seleção acontece na medida em que as rotinas mal-adaptadas caem em desuso e outras, que geram lucros mais elevados, ganham espaço. O que determina as rotinas é a evolução da firma e do seu conhecimento. Para Zawislak (1996, p. 328) "esse estado permanente de aprendizado, acúmulo de experiências e competências, e de busca e aplicação de novas soluções dá à firma o caráter de organismo em constante evolução". À medida que as rotinas vão sendo modificadas por eventos aleatórios, que criam novos problemas a serem solucionados, surge a necessidade de mutação para adaptação das rotinas às novas circunstâncias. Um processo que, do ponto de vista econômico, requer inovação. O quadro a seguir ilustra os paralelos entre a teoria evolucionária de Nelson e Winter e as análises biológicas.

Quadro 2 - Paralelos entre os conceitos da biologia e economia.

\begin{tabular}{|c|c|}
\hline Conceitos da biologia & Contrapartida na economia \\
\hline Organismos individuais (fenótipos) & Firmas \\
\hline Populações & Mercados ou indústrias \\
\hline Genes ou Genótipos & Rotinas \\
\hline Mutação & Inovação \\
\hline Aptidão & Lucratividade \\
\hline
\end{tabular}

Fonte: elaborado a partir de Nelson e Winter (2005, 1977), Possas (2008) e Zawislak (1996).

Observa-se que os organismos individuais correspondem às firmas. Estas, ao fazerem parte de um ambiente competitivo representado pelos mercados ou indústrias, procuram, por meio de suas ações, desenvolver as melhores rotinas para adaptar-se ao ambiente. Existe ainda um feedback entre as rotinas e a inovação, pois ao mesmo tempo em que a inovação cria novas rotinas, estas, ao estarem consolidadas e adaptadas a determinados contextos, acabam incentivado ou restringindo o desenvolvimento de 
novas práticas. As firmas mais aptas, ou seja, as que possuírem um conjunto de rotinas eficientes, terão maior lucratividade e participação no mercado.

Enfim, as rotinas desenvolvidas pelas firmas podem ser vistas como seu conjunto de técnicas. Quando as técnicas estabelecidas são postas à prova por determinados tipos de problemas e não apresentam uma adequada resposta torna-se necessário revisá-las. Então, a inovação consiste em um processo de modificação ou ajuste (mutação) das rotinas. Por isso, é a busca pela solução de problemas aleatórios que acometem no processo de produção. Ou seja, a inovação altera as rotinas e as técnicas procurando solucionar determinados problemas. ${ }^{15}$

\section{0 catchíng up dos países em desenvolvimento: integrando a abordagem neoschumpeteriana}

A Figura 2 sintetiza a proposta teórica para interpretar o desempenho das nações a partir da teoria neoschumpeteriana. Volta-se a afirmar que a compreensão do desenvolvimento deve partir de uma diferenciação desse conceito com o de crescimento. Este último pode não implicar, necessariamente, que o país irá sofrer mudança estrutural, institucional e tecnológica, mas sim que pode apresentar crescimento da renda per capita sem, com isso, aproveitar as oportunidades de se aproximar do nível de desenvolvimento dos países avançados.

Pela ilustração, observa-se que o desenvolvimento ocorre a partir das oportunidades abertas pela explosão de uma nova revolução tecnológica. Ela é responsável pela redefinição do paradigma tecnoeconômico, já que este representa as práticas necessárias ao aproveitamento das oportunidades da revolução em curso. Ou seja, o big bang dá início à definição de novas ótimas práticas que serão utilizadas pelos agentes no processo produtivo. Na visão de Pérez (2004, p. 41): “o surgimento de um novo paradigma tecnoeconômico afeta as condutas relacionadas com a inovação e inversão de tal maneira que pode comparar-se a uma febre do ouro ou o descobrimento de um novo e vasto território".$^{16}$ Com isso, também se delineia

15 Dosi $(1988$, p. 1125) trata a inovação tecnológica como a "[...] solução de problemas - por exemplo, a transformação de calor em movimento, moldar materiais de determinada maneira, produzir componentes com certa propriedade - satisfazendo, ao mesmo tempo, certos requerimentos de custo e comerciabilidade"

16 "El surgimiento de un nuevo paradigma tecnoeconómico afecta las conductas relacionadas con la innovación y la inversión de tal manera que puede compararse a una fiebre del oro o al descubrimiento de un nuevo y vasto território". (PÉREZ, 2004, p. 41) 
uma nova trajetória tecnológica, pois a inovação radical, que normalmente acontece nos países desenvolvidos, tende a seguir um curso específico.

Figura 2 - Proposta de sistematização da teoria neoschumpeteriana do desenvolvimento
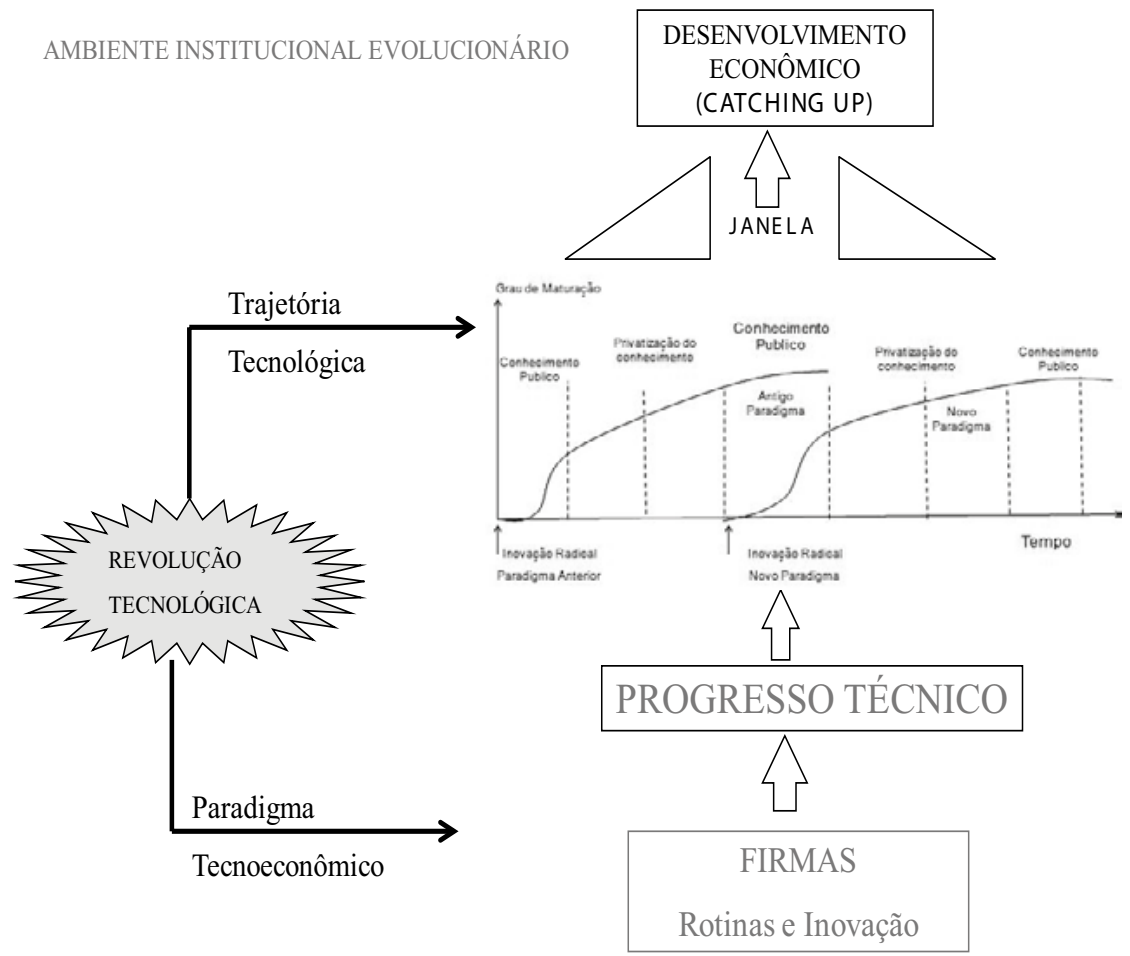

Fonte: elaboração do autor.

Como as revoluções não acontecem no mundo inteiro, o paradigma e a trajetória vão afetar as firmas dos diferentes países, assim como sua atuação e desempenho. Os empreendedores, em conjunto com os diversos atores sociais, alteram suas práticas e são os responsáveis por aproveitar as novas potencialidades que começam a emergir. Eles influenciam e são influenciados pelo paradigma tecnoeconômico que está se desenvolvendo. São os responsáveis por sua aplicação, pois o novo paradigma tende a se tornar um hábito prevalecente entre os diversos agentes do setor produtivo. (PÉREZ, 2004) Daí a importância da interação microeconômica evolucionária com o conceito de revolução e seus desdobramentos, pois as firmas irão se aproveitar das potencialidades na medida em que possuírem e desenvolverem as capacitações necessárias. Dito de outra forma, as condutas das 
empresas afetam diretamente o processo de desenvolvimento na medida em que suas rotinas e sua capacidade de inovação permitem aproveitar a revolução em progresso.

As potencialidades da firma (rotinas e inovação) dependem de um processo histórico e evolucionário. As empresas se desenvolveram por meio da experimentação, de erros e acertos, que definiram sua posição de mercado. Ou seja, suas ações foram selecionadas tanto interna como externamente, sobressaindo-se as mais satisfatórias para a sobrevivência desse organismo. Isso significa que os pontos fortes presentes nas empresas foram evoluindo a partir de processos de seleção e adaptação. Por isso, a compreensão do desenvolvimento exige observar como a evolução de rotinas e da inovação interage com as revoluções tecnológicas e o paradigma tecnoeconômico em curso ou modificação.

Em nível agregado, a conduta das empresas, em conjunto com o paradigma tecnoeconômico emergente, define a evolução tecnológica do país. Esse pode ser entendido como o elemento chave do catching up. Se o objetivo fosse pontuar a instituição mais importante para o desenvolvimento, essa seria o progresso técnico. Porém, é uma instituição dependente das demais e necessita de algumas qualificações. Deve ser compreendida como o desenvolvimento de rotinas que permitem às firmas superar condições adversas. As firmas possuem um conjunto de costumes, desenvolvidos a partir da aprendizagem e que servem para fazer frente aos problemas de projeto, de produto ou de processo. Alguns problemas, no entanto, não são solucionados pelo conjunto de rotinas existente, o que leva à necessidade de novas rotinas e, portanto, do avanço de técnicas. (ZAWISLAK, 1996) Por essa razão, o progresso tecnológico (como instituição do desenvolvimento) deve acontecer a partir das inovações do plano microeconômico, que modificam as rotinas das firmas na busca por melhor posicionamento no mercado. As inovações tecnológicas ainda devem estar em condições de acontecer em conformidade com as oportunidades da revolução em curso, ou, mais precisamente, aproveitando-se a janela aberta em cada ciclo de inovações tecnológicas. Inovações fora do contexto de evolução das tecnologias não serão capazes de subsidiar o avanço dos países menos desenvolvidos rumo às economias avançadas. Ainda cabe pontuar que esse aproveitamento tecnológico deve ser viabilizado pelas demais instituições socioeconômicas e estas devem ser flexíveis o suficiente para permitir a mudança e o aproveitamento das novas possibilidades. O progresso técnico e a evolução institucional devem se disseminar pela nação a ponto de definir novas tecnologias sociais, conforme proposto por Nelson e Sampat (2001) e Nelson (2008). 
Embora o progresso técnico possa ser desenvolvido no contexto de poucas firmas que são economicamente de "ponta", deve se propagar na sociedade criando novas tecnologias sociais, já que estas podem ser encaradas como a disseminação de práticas que permitem melhores condições produtivas. Nelson e Sampat (2001) e Nelson (2008) vão além, demonstrando que as tecnologias sociais ${ }^{17}$ são uma forma de incorporar as instituições diretamente em uma teoria da produção. Extrapolam o nível da firma porque se referem a maneiras padrão e esperadas de interação entre os agentes econômicos na busca de determinados resultados.

Em outras palavras, as tecnologias sociais podem ser vistas como o compartilhamento de rotinas no sistema produtivo da sociedade, ou seja, uma forma do progresso técnico avançar. Se estiverem de acordo ou acontecerem a partir da revolução tecnológica, assemelham-se ao conceito de paradigma tecnoeconômico, embora o mesmo englobe uma dimensão mais macro ou mesoeconômica. As tecnologias sociais, as rotinas e o progresso técnico não podem estar dissociados do conceito de paradigma, já que representam disseminações de práticas comuns para atingir melhores resultados econômicos.

Assim como as rotinas e empresas, o avanço das técnicas no âmbito da sociedade está sujeito a um processo evolucionário. Na visão de Nelson (2006, p. 91), o progresso técnico "[...] se processa inevitavelmente através da geração de uma série de novos pontos de partida concorrendo uns com os outros e com as práticas vigentes". Em vez da metáfora biológica, no entanto, o autor prefere a noção de evolução cultural. Isso porque a tecnologia tende a se tornar pública e, com isso, as aptidões de todos são melhoradas por meio dos esforços de alguns. As tecnologias se tornam comuns na medida em que o tempo passa e que o conhecimento privado, alcançado mediante esforços de Pesquisa e Desenvolvimento (P\&D), se torna compartilhado. ${ }^{18}$ Por isso, o progresso técnico, assim como as tecnologias sociais, as rotinas e inovação são influenciados pela cultura e pela aprendizagem humana. Para Nelson (2007), os ganhos de produtividade (crescimento) requerem modificação nos fatores físicos e nas tecnológicas sociais; requerem que novas formas de fazer as coisas apareçam enraizadas na sociedade. Para o autor, a força motriz de catching up é a assimilação, aprender a fazer efetivamente o que os países de fronteira vêm fazendo.

17 Para Nelson (2008), as tecnologias sociais, em conjunto com as físicas e o suporte institucional adequado, são os elementos chave na obtenção do desenvolvimento.

18 Para Nelson (2006), a generalização desse conhecimento, embora pareça sem muita lógica, é um fator determinante no desenvolvimento. Nesse processo, a concorrência capitalista joga um papel fundamental, porque seleciona as melhores práticas e as dissemina como forma de melhorar os indicadores de desempenho da economia. 
Esse processo de evolução cultural depende, inevitavelmente, da diversidade de instituições presentes na economia, ou seja, como a mudança técnica é um processo evolucionário, reflete a estrutura institucional particular dos países capitalistas. (NELSON, 1988) Nelson e Winter (1977) já haviam observado que o papel das instituições é amenizar a incerteza presente no processo inovativo e que uma estrutura institucional eficiente deve ser capaz de selecionar as inovações e tecnologias mais eficazes, de modo a aceitar e difundir as boas práticas e eliminar as más. Outro elemento importante a ser destacado é que a revolução tecnológica, a utilização do fator chave a ela relacionado e as novas tecnologias requerem mudança institucional. ${ }^{19}$ Pérez (1983) afirma que as transformações observadas na esfera produtiva, com difusão do novo padrão tecnológico, carecem de inovações socioinstitucionais para garantir as potencialidades da nova fase de desenvolvimento.

Não é por acaso que os neoschumpeterianos fazem alusão ao Sistema Nacional de Inovações (SNI) como fator determinante do processo de arranque e disseminação das inovações. (CONCEIÇÃO, 2012) Parece haver acordo entre autores dessa abordagem sobre o fato de as instituições serem elemento de grande relevância para compreender a coevolução tecnológica. Nelson (2007) demonstra que a análise requer muito mais do que as tradicionais instituições envolvidas na atividade produtiva, tais como firmas, bancos, mercados e estado (como responsável por regular as falhas de mercado). O autor afirma que o sistema de inovação deve abranger "[...] a vasta gama de instituições que estão envolvidas no apoio e orientando a dinâmica da atividade econômica, onde a inovação é a força motriz essencial". ${ }^{20}$ (NELSON, 2007, p. 18) Entre elas estão um sistema financeiro forte (público e privado), uma educação primária e secundária adequada, universidades com formação de cientistas e engenheiros capazes de operar novas tecnologias, laboratórios públicos e privados de $\mathrm{P} \& \mathrm{D}$, mecanismos de incentivo à cooperação entre firmas, entre outras. Pérez (1992, p. 59) afirma que um sistema nacional de inovação que tenha resultado efetivo para aproveitar-se das janelas de oportunidade deve ser

19 No conceito de tecnologias sociais, por exemplo, Nelson (2008) demonstra que a interação entre os agentes no processo de produção e a nova forma de realizar as tarefas, definidas por Nelson e Winter (2005) como as rotinas, requer um novo conjunto de instituições. Estas possuem uma definição ampla, pois devem ser entendidas como as estruturas e forças que apoiam e sustentam as tecnologias sociais. 20 " $[. .$.$] the wide range of institutions that are involved in supporting and orienting the dynamics of$ economic activity where innovation is the key driving force". (NELSON, 2007, p. 18) 
um conjunto de esquemas de comportamento profundamente enraizado nas instituições que abrigam os principais atores econômicos e que formam uma rede de interação coerente capaz de harmonizar os esforços das organizações públicas e privadas em torno de um objetivo comum. ${ }^{21}$

Portanto, a estrutura institucional particular de um país em desenvolvimento é fundamental para seu catching up, na medida em que oferece os estímulos para inovação e progresso tecnológico. Por outro lado, por ser path dependence, ${ }^{22}$ a matriz institucional pode ficar locked in, oferecendo empecilhos para que as novas técnicas, expressas no paradigma tecnoeconômico, sejam aproveitadas pelos países em desenvolvimento.

No âmbito microeconômico, as firmas são os agentes que assumem a maior responsabilidade por colocar em prática as inovações para a emergência de novas técnicas, mas isso depende do marco institucional da economia. Mais uma vez, contudo, cabe destacar que o desenvolvimento econômico e o catching up somente serão alcançados se observadas as potencialidades da revolução tecnológica em curso, o paradigma tecnoeconômico e a janela de oportunidade. Nelson (2007) argumenta que a inovação é a chave para o desenvolvimento e não existe catching up sem inovação. Porém, a inovação necessita fazer parte do novo paradigma e ser implementada quando se abre a janela de oportunidade.

As possibilidades para o catching up acontecem nas fases inicias da revolução tecnológica, pois na medida em que as tecnologias se tornam maduras, as probabilidades de um salto de desenvolvimento se reduzem. (PÉREZ, 2001, 2004) Assim, quanto mais próximo do big bang ou do surgimento das novas tecnologias, maiores as chances de alcançar os países de ponta. Isso porque, nas primeiras fases, a lucratividade associada às inovações é alta, existe grande potencial de crescimento do mercado, os custos de investimento em equipamentos são baixos e é possível melhorar

21 "um conjunto de esquemas de comportamiento profundamente arraigado em las instituiciones que albergan a lós principales actores económicos y en cual conforma una red de interacción coherente capaz de armonizar lós esfuerzos de las organizaciones públicas e privadas hacia un objetivo nacional común". (PÉREZ, 1992, p. 59)

22 Douglass $C$. North, apesar de não ser um dos representantes da teoria evolucionária neoschumpeteriana, mas sim um novo-institucionalista, tem feito grandes avanços ao explicar a inércia institucional que ocorre porque existem incentivos (externalidades ou aprendizado) que prendem uma nação em determinada trajetória. A estabilidade institucional também é influenciada por grupos de interesse que moldam as instituições segundo seus desejos. (NORTH, 1995) Nas suas obras mais recentes, tal como em North (2005), o autor tem avançado em sua análise sobre a dinâmica institucional incorporando o papel dos modelos cognitivos que podem impedir ou facilitar a mudança econômica. 
a produtividade. Embora o conhecimento científico para ingressar nas fases iniciais da revolução seja relevante, ele tende a estar disponível, por exemplo, em órgãos de pesquisa governamentais e universidades.

A importância da fase de maturação, por outro lado, não deve ser menosprezada. (PÉREZ, 2001) Embora seja o período em que a utilização das tecnologias é disseminada, oferece claras possibilidades para que os países internalizem as práticas já existentes, reunindo condições para o crescimento. É uma fase que possibilita aprendizagem e geração de infraestrutura para viabilizar o ingresso de forma mais efetiva no novo paradigma. Assim, as oportunidades para nova fase produtiva são maiores em dois momentos: nas primeiras fases de deflagração do big bang e na sua fase de maturação. Não por acaso, Pérez (1992) afirma tratar-se de um momento de dupla oportunidade tecnológica. Isso porque na fase de maturação do antigo paradigma tecnoeconômico e na fase de difusão inicial do novo, o conhecimento sobre as melhores práticas é publico e a experiência técnica e know-how não são determinantes na apropriação da tecnologia.

Em suma, o que se procurou demonstrar nesse item é que a revolução tecnológica define o paradigma tecnoeconômico, responsável por disseminar as melhores ações para atingir as metas econômicas. As firmas desenvolvem suas atividades num contexto de modificação de paradigma e suas práticas passam por um processo de evolução, conforme a metáfora evolucionista. Suas ações, representadas nas rotinas, estão sujeitas a um processo de seleção e adaptação a partir dos mecanismos de mercado. O progresso tecnológico que ocorre nas empresas e se torna uma prática social sofre do mesmo processo, sendo afetado ainda pelas instituições e pelo sistema nacional de inovações. O fundamental, contudo, é observar que o catching up dos países requer que seja aproveitada a janela de oportunidade que se abre na fase de maturação do antigo paradigma e surgimento do novo. Em outras palavras, o timing em que o paradigma tecnoeconômico é aproveitado por um país é determinante para seu avanço. Nesse processo, o estado joga um papel fundamental, pois, além de afetar o ambiente de regulação e direcionar as políticas ao aproveitamento das novas potencialidades, é o responsável por formular uma estratégia de desenvolvimento coerente com as transformações em curso. Essa estratégia implica planejamento e a união das diversas classes da sociedade em torno de um objetivo comum. ${ }^{23}$ Pérez (1992) demonstrou que o estado é agente

23 O texto de Bresser-Pereira (2006) é um exemplo de como a estratégia nacional de desenvolvimento se torna uma instituição ao congregar os diversos atores sociais em busca do crescimento. Isso contrasta com a teoria liberal ortodoxa sobre o papel do Estado, pois, conforme demonstrou Chang (2004), a estratégia, implementada na forma de política, é imprescindível para catching up das nações menos desenvolvidas. 
fundamental para a reestruturação competitiva das empresas e ingresso no novo paradigma tecnoeconômico. Para a autora, o estado deve eliminar os excessos de intervenção, estimulando as empresas mais aptas ao progresso técnico. O Estado também deve oferecer recursos facilitadores para as empresas com maior capacidade competitiva (recursos financeiros, recursos humanos e serviços de infraestrutura). Enfim, deve promover e orientar a mudança, mediante a criação de instituições adequadas e fomento ao sistema nacional de inovações. ${ }^{24}$

\section{Considerações finais}

O trabalho apresentou o objetivo de integrar a teoria microeconômica evolucionária com a ideia de revoluções tecnológicas e seus desdobramentos, reunindo elementos que auxiliam na explicação do desenvolvimento econômico (catching up) das nações ao longo do tempo. Dessa forma, procurou construir uma ponte entre diversos teóricos, embora em cada um deles fosse possível encontrar elementos para compreensão da performance das nações.

O conceito de desenvolvimento foi tratado a partir da possibilidade dos diversos países alcançarem os desenvolvidos (de ponta). Assim, observou-se que o catching up requer a análise das potencialidades abertas por uma revolução tecnológica e disseminação do novo paradigma tecnoeconômico. A esse respeito, as inovações devem ser implementadas em um momento estratégico, ou seja, nas fases iniciais de surgimento do novo paradigma tecnoeconômico, desde que o paradigma anterior tenha contribuído com os pré-requisitos para aproveitar as transformações em curso.

Dada a revolução tecnológica e as novas práticas de produção, as empresas, no plano micro, assumem papel decisivo. São elas as responsáveis diretas pela aplicação das novas práticas no processo produtivo. As firmas, com apoio das instituições e do SNI, são responsáveis pelas inovações, de forma a viabilizar o aproveitamento das janelas de oportunidade. Por isso, o progresso técnico, ao disseminar-se pela sociedade, pode ser entendido como elemento chave do desenvolvimento econômico.

Por fim, cabe destacar que a proposta de sistematização teórica a partir da abordagem neoschumpeteriana é indispensável para compreender as

24 No paradigma de produção em massa, Pérez $(1983 ; 1992)$ destaca a importância das políticas de Estado keynesianas para promoção do desenvolvimento. As inovações institucionais promoveram o crescimento da demanda necessária à consolidação dessa forma de utilização das novas tecnologias (políticas fiscais e monetária, déficit público, sindicalização, seguridade social, etc.). 
diferenças de desenvolvimento entre as nações. Na atualidade, entender o desenvolvimento requer observar como as nações inseriram-se na quinta revolução tecnológica e no paradigma da microeletrônica. Da mesma forma, é possível compreender como irão se aproveitar da próxima revolução que, em conjunto com a atual, irá abrir novas possibilidades, mas também a necessidade de mudança técnica e institucional.

\section{Referências}

ABRAMOVITZ, M. Catching up, forging ahead and falling behind. Journal of Economic History, New York, v. 46, n. 2, p. 385-406, June 1986.

BRESSER-PEREIRA, L. C. National development strategy: the key economic growth institution. São Paulo, 2006. Disponível em: < http://vision.cer.uz/ Data/lib/readings/development_models/DEV_National_dev_strategy_key_for_ frowth_institutions_EN_2006.pdf > . Acesso em: 2 maio 2011.

CHANG, H. Chutando a Escada: a estratégia do desenvolvimento em perspectiva histórica. São Paulo: Edunesp, 2004. 266 p.

CONCEIÇÃO, O. A. C. Instituições, crescimento e mudança na ótica institucionalista. Porto Alegre: FEE, 2002. 227 p.

CONCEIÇÃO, O. A. C. Há compatibilidade entre a "tecnologia social" de Nelson e a "causalidade vebleniana" de Hodgson? Revista de Economia Política, São Paulo, v. 32, n. 1 (126), p. 109-127, jan./mar. 2012.

DOSI, G. Sources, Procedures and Microeconomic Effects of Innovation. Journal of Economic Literature, Nashville, Tenn., v. 26, n. 3, p. 1120-1171, Sept. 1988.

DOSI, G. Technological paradigms and technological trajectories: A suggested interpretation of the determinants and directions of technical change. Research Policy, Amsterdam, v. 22, n. 2, p. 102-103, Apr. 1993.

HODGSON, G. M. Economia e evolução: o regresso da vida à teoria econômica. Oeiras: Celta, 1997. 364 p.

KUHN, T. S. A estrutura das revoluções científicas. 3. ed. São Paulo: Perspectiva, 1992. 257 p.

NELSON, R.; SAMPAT, B. N. Las instituiciones como factor que regula el desempeño econômico. Revista de economia institucional, Bogotá, v. 2, n. 5, p. 17-51, 2001. 
NELSON, R.; WINTER, S. G. Uma teoria evolucionária da mudança econômica. Campinas, SP: Ed. Unicamp, 2005. 631 p.

NELSON, R.; WINTER, S. G. In search of useful theory of innovation. Research Police. Amsterdam, v. 6, n. 1, p. 36-76, Jan. 1977.

NELSON, R. As fontes do crescimento econômico. Campinas, SP: Ed. Unicamp, 2006. 501 p.

NELSON, R. Economic Development from the perspective of evolutionary economic theory. Working papers in Technology Governance and Economic Dynamics, n. 2, Jan. 2006.

NELSON, R. What enables rapid economic progress: What are the needed institutions? Research Policy, Amsterdam, v. 37, p. 1-11, 2008.

NELSON, R. Institutions supporting technical change in the United States. In: DOSI, G. et al. Technical Change and Economic Theory. London; New York: Pinter Publishers, 1988. p. 312-329.

NORTH, D. C. Institutions, institutional change and economic performance. Cambridge, Mass.: Cambridge University Press, 1995. 152 p.

NORTH, D. C. Understanding the process of economic change. Princeton, NJ: Princeton University Press, 2005. 187 p.

PÉREZ, C.; SOETE, L. Catchin up in technology: entry barriers and Windows of opportunity. In: DOSI, G. et al. Technical Change and Economic Theory. London: New York: Pinter Publishers, 1988. p. 458-479.

PÉREZ, C. Cambio técnico, restructuración competitiva y reforma institucional en los países en desarrollo. El trimestre económico, México, v. 1, n. 233, p. 23-64, enero/marzo. 1992.

PÉREZ, C. Cambio estructural y asimilación de nuevas tecnologías en el sistema económico y social. Futures. v. 15, n. 4, p. 357-375, Oct. 1983. (Tradução do inglês).

PÉREZ, C. Cambio tecnológico y oportunidades de desarollo como Blanco móvil. Revista de la CEPAL, Santiago de Chile, n. 75, p. 115-136, dic. 2001.

PÉREZ, C. Revoluciones tecnológicas y capital financiero: la dinâmica de las grandes burbujas financieras y las épocas de bonanza. México: Siglo XXI, 2004. 269 p.

PÉREZ, C. Technological revolutions and techno-economic paradigms. Working Papers in Technology Governance and Economic Dynamics, n. 20, Jan. 2009. 
POSSAS, M. L. Economia evolucionária neo-schumpeteriana: elementos para uma integração micro-macrodinâmica. Estudos avançados, São Paulo, v. 22, n. 63, p. 281-305. 2008.

ROSENBERG, N. Por dentro da caixa-preta: tecnologia e economia. Campinas, SP: Ed. Unicamp, 2006. 430 p.

SIMON, H. A. Comportamento administrativo: estudo dos processos decisórios nas organizações administrativas. Rio de Janeiro: FGV, 1965. 311 p.

SIMON, H. A. Rationality in psychology and economics. The Journal of Business, Chicago, v. 59, n. 4, p. 209-224, Oct. 1986.

SCHUMPETER, J. A. Capitalismo socialismo e democracia. Rio de janeiro: Zahar, 1984. 534 p.

SCHUMPETER, J. A. Teoria do desenvolvimento econômico: uma investigação sobre lucros, capital, credito, juro e o ciclo econômico. São Paulo: Nova Cultural, 1985. $169 \mathrm{p}$.

VELHO, L. Apresentação ao texto "The determinants of innovation" de Christopher Freeman. Revista Brasileira de Inovação. Rio de Janeiro, v. 9, n. 2, p. 215-230, jul./dez. 2010.

ZAWISLAK, P. A. Uma abordagem evolucionária para casos de atividade de inovação no Brasil. Ensaios FEE. Porto Alegre, v. 17, n. 1, p. 323-353, 1996. 
